\title{
Traffic Conflict Technique-Based Setting Method of Freeway Climbing Lane
}

\author{
Xin Gu, QiaoJun Xiang and Shen Li \\ Southeast University, School of Transportation, 210096 Si Pai Lou \#2, Nanjing, China
}

\begin{abstract}
Speed of heavy vehicles is greatly reduced on upgrade sections due to their insufficient climbing capability, thus having great impact on traffic safety. Setting climbing lanes can solve this problem effectively. Considering China's traffic composition and operational status, this paper proposed the traffic conflict technique-based setting method of freeway climbing lanes in order to set foundations for climbing lanes with the goal of promoting traffic safety. Based on large freeway upgrade section data and actual traffic characteristics, the paper built simulation models with VISSIM. 220 schemes were simulated by setting different road and traffic conditions of models. The paper then used Surrogate Safety Assessment Model (SSAM) to calculate traffic conflict, analyzed the influence of slope, slope length and mixed rate of heavy vehicles on traffic safety on upgrade sections. Finally, taking the reduction extent of the collision rate after setting climbing lanes as an indicator, this paper used K-means to classify the effectiveness level of the climbing lanes. The paper found the setting position and basis of the climbing lanes. The findings of this paper can provide support to effective decision making with regards to constructing future climbing lanes.
\end{abstract}

\section{Introduction}

Heavy vehicles usually have a great speed reduction on upgrade sections, due to their insufficient climbing capability, which has effect on the traffic safety. Setting climbing lanes on the upgrade sections would be an effective strategy to lessen this negative impact. However, since the construction of climbing lanes entails large difficulties and high construction cost, it is necessary to demonstrate the rationality of setting climbing lanes on upgrade sections of freeways.

Currently much research on setting methods and effects of setting climbing lane has been studied. Hesham Rakha and Bin Yu utilized a linearly increasing variable power vehicle dynamics model to develop the TRUCKSIM software for the modeling of truck acceleration behavior along grade sections. Using the software, the sensitivity of truck performance curves to roadway and truck characteristics are quantified [1]. Bin Yu's research also demonstrates that the vehicle weightto-power ratio, vehicle power, and pavement condition are critical variables in designing truck climbing lanes [2]. Other Researchers also propose climbing lane setting methods based on traffic capacity [3]-[5]. Venkataraman Shankar evaluated the effect of climbing lane from the speed difference [6]. Abishai Pomst's results show that setting climbing lane can improve traffic flow, safety and capacity [7]. LIANG Guohua analyzes the influence of number of lanes, slope, slope length, speed and mixed rate of heavy vehicles on traffic capacity in climbing section to test the effectiveness of building climbing lane [8].

Other studies show the different climbing lane setting standards. American studies show the deviation between running speed of heavy vehicle and the average running speed on a given longitudinal gradient section is bigger, the chance of accidents occurring is higher. Therefore, AASHO requires that climbing lanes should be set on sections where the speed of large vehicles is reduced by $16 \mathrm{~km} / \mathrm{h}$ than its initial speed from the start of the gradient [9], [10]. In the Investigation and Research Report on Climbing Lanes, Japan adopts a simulation method to determine the appropriate sections and conditions of setting climbing lanes based on the aspects of traffic service and traffic safety [11]. China Academy of Transportation Science proposes the maximum limits on the slope and length of longitudinal gradient of all levels of highways, based on the vehicular speed differences and the requirements of satisfying the highway service level demands [12]-[14].

From the literature review, there seems to be three main issues in China: 1) most calculation methods used in setting conditions and sections of climbing lanes in China are based on the research results from other countries. The fact, traffic composition and the dynamic performance of the large vehicles in China are greatly different from those of other countries, is not taken into account. This may cause improper climbing lanes setting; 2) most studies only consider capacity rather than traffic safety; 3) the current foundations of setting climbing 
lanes are not qualified in detail. So in practice, decisions on constructing climbing lanes are based on the subjective judgments of the designers.

In order to address these issues, this paper proposes the traffic conflict technique-based setting method. This method perfects the foundations of climbing lanes setting with regard to traffic safety. Traffic conflict technique is an approach that overcomes the lack of reliable accident records, relying instead on observations of conflicts [15]. Microscopic simulation models are also seen as promising tools to evaluate road safety levels of existing and future infrastructures [16]. The VISSIM simulation model and Surrogate Safety Assessment Model (SSAM) have been proven to provide reasonable estimates for field measured traffic conflicts [17].The main object of this study is to find suitable climbing lane setting standard for China in terms of traffic safety. Actual typical upgrade section data has been surveyed in order to obtain actual traffic characteristics. The research can provide effective decision support for managers to set up climbing lanes.

\section{Method}

\subsection{Data Collection}

The traffic survey was conducted at an upgrade section of Nanjing-Hangzhou Highway (Section No. K2092+000 $\mathrm{K} 2093+800$ ), which has slope length of $1800 \mathrm{~m}$, gradient of $2.9 \%$, vertical curve radius of $20000 \mathrm{~m}$, one-way for two lanes and one lane width $3.75 \mathrm{~m}$. We divided the upgrade section into ten point to collect traffic data, such as the volume of different vehicles, the running speeds on different sections etc. (Fig. 1).

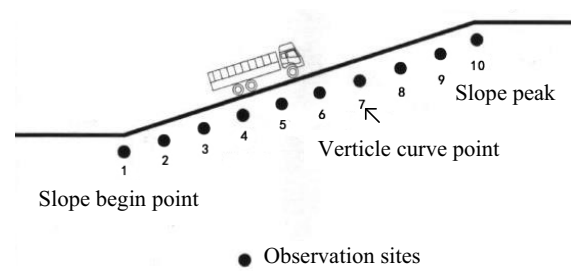

Figure 1. Distribution of observation points

\subsection{VISSIM-Based simulation model of the upgrade sections}

\subsubsection{Model assumption}

Specific to the characteristics of the upgrade sections and the functions of the simulation software, there are four assumptions:

- Neglect the influence of horizontal curve and simplify the horizontal alignment of upgrade sections into straight lines. Just consider the geometrical parameters such as slope, length and width of the lane in the design of the simulation experiment.

- Take the vertical curve on the top of slope as straight line of the upgrade sections. Neglect the running speed difference caused by the difference of the lengths of vertical curve.
- Neglect the influence of the lateral clear width on the operation characteristics of the traffic flow.

- The design speed is $100 \mathrm{~km} / \mathrm{h}$.

\subsubsection{Parameter calibration}

Traffic Parameters Calibration of Representative Vehicles :In the simulation, we categorize vehicles into two categories, small cars (Car) and heavy vehicles $(\mathrm{HGV})$, one have large flow and another have poor climbing performance. Meanwhile, combining the analysis of vehicle performance and driving behavior, we choose VW PASSAT as the representative for Cars and DFM EQ5208XXY2 as the representative of HGV.

Calibration of the Drivers' Behavior: We calibrate the drivers' behavior parameters from the following three models: the car-following model, the lane-changing model and the transverse behavior model [18]. In this paper, we adopt the Wiedemann99 Car-following model which can simulate the traffic flow characteristics of highway sections.

Simulation Time Period and Number of Times: Traffic collision is randomly time-varying. To eliminate the influence of time, this paper sets the simulation period as 43,200 s, i.e. 12 hours. Meanwhile, to eliminate the influence of random factors in single simulation, we simulate each assumption 10 times and adopt the average value of the total 10 simulations.

\subsubsection{Model verification}

Table 1. Speeds and traffic flow test.

\begin{tabular}{|c|c|c|c|c|c|}
\hline \multirow{7}{*}{$\begin{array}{r}\text { Speed } \\
\text { Test }\end{array}$} & \multicolumn{2}{|c|}{$\begin{array}{l}\text { Vehicle Types } \\
\text { and Sections }\end{array}$} & $\begin{array}{c}\text { Actual } \\
\text { Value }(k m / h)\end{array}$ & $\begin{array}{c}\text { Simulation } \\
\text { Value }(\mathbf{k m} / \mathbf{h})\end{array}$ & $\begin{array}{c}E \\
(\%)\end{array}$ \\
\hline & \multirow{3}{*}{$\begin{array}{l}\mathrm{Ca} \\
\mathrm{rs}\end{array}$} & Section 1 & 93.43 & 92.2 & 1.32 \\
\hline & & Section 4 & 90.51 & 90.7 & 0.21 \\
\hline & & Section 7 & 88.87 & 86.4 & 2.78 \\
\hline & \multirow{3}{*}{$\begin{array}{c}\mathrm{H} \\
\mathrm{G} \\
\mathrm{Vs} \\
\end{array}$} & Section 1 & 70.1 & 72.5 & 3.42 \\
\hline & & Section 4 & 60.39 & 49.7 & 1.14 \\
\hline & & Section 7 & 42.43 & 44.5 & 4.88 \\
\hline \multirow{7}{*}{$\begin{array}{l}\text { Traffic } \\
\text { Flow } \\
\text { Test }\end{array}$} & \multicolumn{2}{|c|}{$\begin{array}{l}\text { Time Interval } \\
\text { (min) }\end{array}$} & $\begin{array}{c}\text { Actual } \\
\text { Observed } \\
\text { No. of } \\
\text { Vehicles } \\
\end{array}$ & $\begin{array}{c}\text { No. of } \\
\text { Vehicles in } \\
\text { simulation } \\
\text { experiments }\end{array}$ & $\begin{array}{c}E \\
(\%)\end{array}$ \\
\hline & \multicolumn{2}{|r|}{$0 \sim 5$} & 55 & 53 & 3.64 \\
\hline & \multicolumn{2}{|r|}{$5 \sim 10$} & 47 & 46 & 2.13 \\
\hline & \multicolumn{2}{|r|}{$10 \sim 15$} & 50 & 48 & 4.00 \\
\hline & \multicolumn{2}{|r|}{$15 \sim 20$} & 55 & 57 & 3.64 \\
\hline & \multicolumn{2}{|r|}{$20 \sim 25$} & 42 & 44 & 4.76 \\
\hline & \multicolumn{2}{|r|}{$25 \sim 30$} & 44 & 42 & 4.76 \\
\hline
\end{tabular}

We carry out the simulation by setting up a simulation network of upgrade sections in the VISSIM, and taking the values of traffic flow, ratio of heavy vehicles etc. as input parameters, which are obtained from the practical survey and statistical results. Test simulation model by two indicators, average speed of each section and the traffic flow. The verification result is shown in Table 1 . In addition, we also use root-mean-square percent error (RMSP), correlation coefficient $\mathrm{R}$ and Hill inequality coefficient $U$ as the testing indexes to verify the effect of the model. Error $\mathrm{E}<5 \%$; it is within the normal range of error and the other three indexes also satisfies the 
requirements $\mathrm{RMSP}<15 \%, \mathrm{r}>0.8, \mathrm{U}<0.3$. Therefore the traffic simulation model is valid.

\subsubsection{Simulation scheme}

On upgrade sections, factors which influence the traffic flow mainly include road conditions (slope of gradient, length, radius of curve, number of lanes, width of lanes etc.), traffic conditions (volume of traffic, traffic composition etc.), environmental conditions (weather conditions, environments along the roads etc.).

This paper establishes kinds of simulations by inputting different traffic conditions and road conditions. We can get different simulation scenarios to analyze traffic operation under different conditions. The specific conditions of simulation schemes are shown in Table 2. In analyzing the combination of different road traffic conditions, a total of 220 schemes have been simulated.

Table 2. Specific values of road conditions and traffic conditions.

\begin{tabular}{|c|c|c|c|c|}
\hline \multirow{4}{*}{$\begin{array}{c}\text { Road } \\
\text { Conditio } \\
\text { ns }\end{array}$} & Slope (\%) & 3 & 4 & 5 \\
\hline & Length(m) & $\begin{array}{c}800 \\
1000 \\
1200 \\
1400 \\
1600 \\
1800\end{array}$ & $\begin{array}{c}600 \\
800 \\
1000\end{array}$ & $\begin{array}{l}600 \\
800\end{array}$ \\
\hline & No. of lanes & \multicolumn{3}{|c|}{ Bi-directional four lanes } \\
\hline & $\begin{array}{l}\text { Width of } \\
\text { Lanes(m) } \\
\end{array}$ & \multicolumn{3}{|c|}{3.75} \\
\hline \multirow{2}{*}{$\begin{array}{c}\text { Traffic } \\
\text { Conditio } \\
\text { ns }\end{array}$} & $\begin{array}{c}\text { Volume of } \\
\text { Traffic(veh/h) }\end{array}$ & \multicolumn{3}{|c|}{$600 、 800 、 1000 、 1200$} \\
\hline & $\begin{array}{c}\text { Ratio of large } \\
\text { vehicles }(\%)\end{array}$ & \multicolumn{3}{|c|}{$10 、 20 、 30 、 40 、 50$} \\
\hline
\end{tabular}

\subsection{SSAM-based conflict analysis}

SSAM operates by processing data describing the trajectories of vehicles driving through a traffic facility, which provided by VISSIM in this paper, and identifying conflicts. For each vehicle-to-vehicle interaction SSAM calculates surrogate measures of safety and determines whether or not that interaction satisfies the criteria to be deemed as conflicts [19]. TTC is a critical parameter, which is defined as the minimum time to collision value observed during the interaction of two vehicles on collision course. If at any time step the TTC drops below a given threshold ( $2 \mathrm{~s}$ in this paper), the interaction is tagged as a conflict. In addition, we don't take PET into account in this paper, so we use its default value. We also take the default value in the setting of the angular range of collisions; it means that when the angle of the collision vehicles satisfies this requirement, the incident will be defined as side collision.

\subsection{K-means-Based safety assessment}

In this paper, we take the reduction of traffic conflict rate as the index to assess the effect of the climbing lanes. And we adopt the K-means algorithm to process the data, since the data are in large amount and discrete. The K- means algorithm is a typical clustering algorithm based on distances and easy to use. Firstly we analyze the data with SPSS to determine the center of the primary categories, then use the K-means algorithm to categorize the data into four categories, i.e. Excellent, Good, Middle and Poor to express the effectiveness of setting climbing lane.

\section{Results}

\subsection{Setting position of the climbing lane}

The scenario whose road with the gradient of $3 \%$, slope length of $1600 \mathrm{~m}$, traffic volume of $1000 \mathrm{veh} / \mathrm{h}$ and heavy vehicle ratio of $30 \%$ is taken as an example. The optimal setting position of climbing lane is determined through analyzing the traffic collisions under different start-end points.

When the climbing lane has not been set, the speed variation tendency of heavy vehicles after entering the upgrade section is obtained through simulation (Fig. 2). As illustrated in Fig. 2, the heavy vehicles have different speed reductions at different sections after entering the upgrade section. Specifically, the sections respectively corresponding to the speed reductions $15 \mathrm{~km} / \mathrm{h}, 20 \mathrm{~km} / \mathrm{h}$, $25 \mathrm{~km} / \mathrm{h}$ and $30 \mathrm{~km} / \mathrm{h}$ are set as the start points of the climbing lane, and the speed recovery positions are respectively set as the end points of the climbing lane. The simulation models of the climbing lane are thus established under the above four conditions. Therein, the transition lengths of the branching section and the confluence section are respectively set as $100 \mathrm{~m}$ and $200 \mathrm{~m}$. The section adjacent to the longitudinal slope is a straight slope, so the length of the additional section is set as $150 \mathrm{~m}$. The traffic conflict distribution under the above four conditions before and after setting climbing lane is obtained through simulation (Table 3 ).

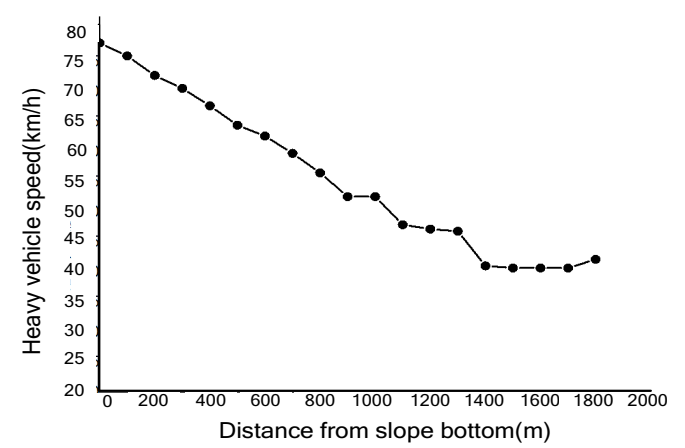

Figure 2. Speed profile of heavy vehicles on the upgrade section.

According to the simulation result, the number of rear-end collisions on the upgrade section is obviously reduced after setting the climbing lane. While the number of side impact collisions is increased, the total number of collisions is reduced. Moreover, when the start point of the climbing lane is set on the section corresponding to the speed reduction $20 \mathrm{~km} / \mathrm{h}$ (namely $700 \mathrm{~m}$ ), the total number of the collisions and the number of rear-end collisions are minimized. The cause analysis is as follows: 
Table 3. Traffic collision distribution under the conditions of different start points of the climbing lane.

\begin{tabular}{|c|c|c|c|c|}
\hline \multicolumn{2}{|c|}{ Setting Condition } & $\begin{array}{c}\begin{array}{c}\text { Number } \\
\text { of Rear- } \\
\text { end }\end{array} \\
\text { Collisions }\end{array}$ & $\begin{array}{l}\text { Number } \\
\text { of Side } \\
\text { Impact } \\
\text { Collisions }\end{array}$ & $\begin{array}{c}\text { Total } \\
\text { Number of } \\
\text { Collisions }\end{array}$ \\
\hline \multicolumn{2}{|c|}{ No Climbing Lane } & 300 & 108 & 408 \\
\hline \multirow{4}{*}{$\begin{array}{l}\text { With } \\
\text { Climbing } \\
\text { Lane }\end{array}$} & $\begin{array}{c}15 \mathrm{~km} / \mathrm{h} \\
\text { Speed } \\
\text { reduction }\end{array}$ & 80 & 219 & 299 \\
\hline & $\begin{array}{c}20 \mathrm{~km} / \mathrm{h} \\
\text { Speed } \\
\text { reduction }\end{array}$ & 24 & 228 & 252 \\
\hline & $\begin{array}{c}25 \mathrm{~km} / \mathrm{h} \\
\text { Speed } \\
\text { reduction }\end{array}$ & 58 & 253 & 311 \\
\hline & $\begin{array}{l}30 \mathrm{~km} / \mathrm{h} \\
\text { Speed } \\
\text { reduction }\end{array}$ & 126 & 224 & 350 \\
\hline
\end{tabular}

When the start point of the climbing lane is set on the section corresponding to the speed reduction $15 \mathrm{~km} / \mathrm{h}$ (namely $400 \mathrm{~m}$ ), the heavy vehicle needs to have additional speed reduction to travel to the climbing lane, thus causing more rear-end collisions with the vehicles on the main lane. When the start point is set at the section corresponding to the speed reduction $25 \mathrm{~km} / \mathrm{h}$ (namely $900 \mathrm{~m}$ ), at the middle position of the upgrade section, such climbing lane setting can effectively reduce the number of the collisions between the middle and top upgrade section.

When the start point of the climbing lane is set at the section corresponding to the speed reduction $30 \mathrm{~km} / \mathrm{h}$ (namely $1000 \mathrm{~m}$ ), the speed of the large vehicle has been reduced to the balanced speed. The speed difference between small vehicles and large vehicles is then gradually stabilized, such that the climbing lane can no longer effectively reduce the number of the traffic collisions.

According to above analysis, when the section corresponding to the speed reduction $20 \mathrm{~km} / \mathrm{h}$ of the heavy vehicles is set as the start point of the climbing lane, the number of the traffic collisions can be effectively reduced, thus achieving the optimal effect. Therefore, the speed reduction $20 \mathrm{~km} / \mathrm{h}$ is set in the article as the basis for setting the start point of the climbing lane.

\subsection{Effect analysis for the setting of the climbing lane}

The reduction extent of traffic conflict rate after setting climbing lane on the freeway upgrade section is related to the slope length, the gradient, the traffic volume and the large vehicle rate, as shown in Fig. $3(\mathrm{a} \sim \mathrm{d})$.

According to Fig. 3 (a), under the same ratio of large vehicle, the reduction extent of collision rate is overall slightly increased along with the increment of the gradient; according to Fig. 3 (b), under the same traffic volume, the reduction extent of collision rate is increased along with the increment of the slope length.

According to Fig. 3 (c), under the same ratio of large vehicle, the collision rate reduction extent of the upgrade section is $10 \% \sim 20 \%$, and significantly influenced by the traffic volume. Specifically, when the ratio of large vehicle is relatively small (less than $30 \%$ ), the reduction extent of collision rate is firstly increased and then reduced along with the increment of the traffic volume. When the traffic volume is $1200 \mathrm{veh} / \mathrm{h}$, the reduction extent of collision rate reaches to the maximum value. When the ratio of large vehicle is relatively large (more than $30 \%$ ), the reduction extent of collision rate reaches to the maximum value at the traffic volume of $1000 \mathrm{veh} / \mathrm{h}$.

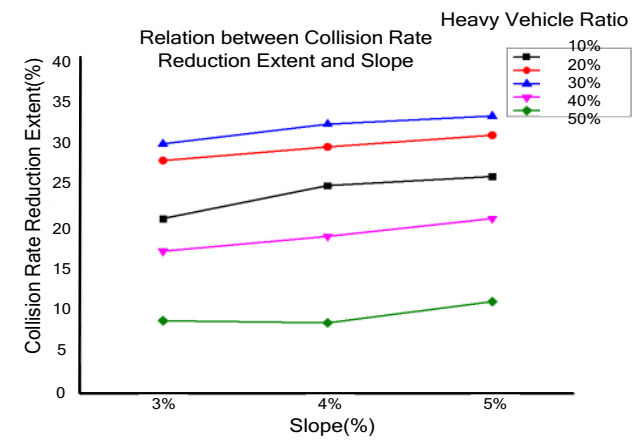

(a)

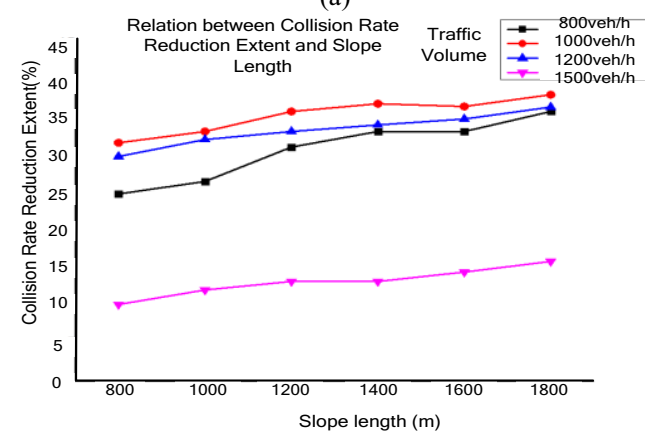

(b)

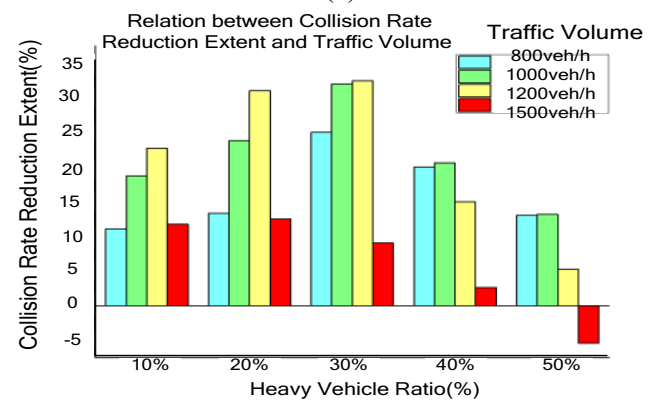

(c)

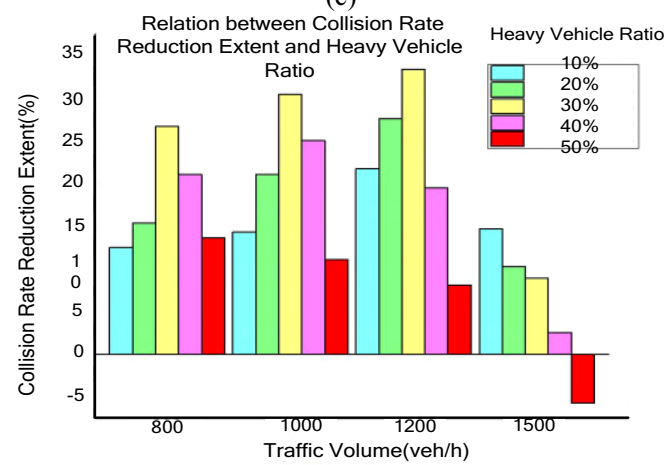

(d)

Figure 3. Results.

The analysis is as follows: when the traffic volume is relatively small, vehicles have high running freedom and small mutual influence. So the setting of the climbing lane cannot obviously improve traffic safety. Along with the increment of the traffic volume, large vehicles 
gradually significantly influence small vehicles, and the small vehicles need to find suitable opportunities to change lane for overtaking. At this moment, if the climbing lane is set, most of the large vehicles will be separated to the climbing lane, thus effectively reducing the influence on small vehicles, reducing the speed change requirements of small vehicles for lane change. Finally this can reduce vehicle collisions and improve traffic safety.

When the traffic volume reaches to a certain value, the traffic flow on the upgrade section is under following driving state. Small vehicles rarely have space to change lane for overtaking, so the vehicle collision is small. Large vehicles are also not the main factor influencing the traffic safety of the upgrade section. So setting climbing lane in this occasion only has small effect for traffic safety improvement, and may increases the lane change requirements of some large vehicles, thus increasing rather than reducing the traffic collision rate.

According to Fig.3 (d), when other conditions are not changed, the reduction extent of collision rate presents a parabola form along with the change of the large vehicle ratio. Under the condition that the traffic volume is not more than $1200 \mathrm{veh} / \mathrm{h}$, when the large vehicle rate is $30 \%$, the reduction extent of collision rate reaches to the maximum value. When the large vehicle ratio is less than $30 \%$, the reduction extent of collision rate is increased along with the increment of the large vehicle ratio. When the large vehicle ratio is more than $30 \%$, the reduction extent of collision rate is reduced along with the increment of the large vehicle ratio.

Under the condition that the traffic volume is more than $1200 \mathrm{veh} / \mathrm{h}$, when the large vehicle ratio is $10 \%$ and $20 \%$, the reduction extent of collision rate is relatively large. When the large vehicle ratio is more than $20 \%$, the reduction extent of collision rate is reduced along with the increment of the large vehicle ratio.

\subsection{Effectiveness evaluation}

$K$-mean is adopted for the effectiveness evaluation of the data obtained thereby. The final clustering result obtained from ten iterations is shown in Fig. 4.

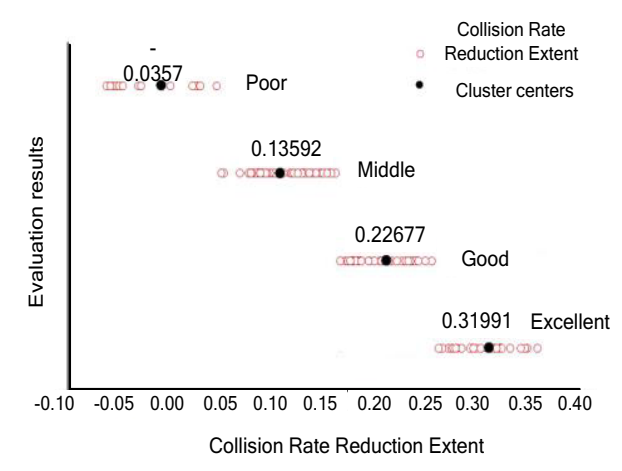

Figure 4. Collision rate clustering result in simulation experiment.

According to the cluster results, we classify the effectiveness of the climbing lanes into four levels. If the reduction extents of traffic collision rate $(C R)>0.31991$, it's excellent; if $0.22677<\mathrm{CR}<0.31991$, it's good; if
$0.13592<\mathrm{CR}<0.22677$, it's Middle; if $\mathrm{CR}<0.13592$, it's poor.

The upgrade section with slope length of $1200 \mathrm{~m}$, gradient of $3 \%$, traffic volume of $800 \mathrm{veh} / \mathrm{h} \sim 1500 \mathrm{veh} / \mathrm{h}$, and large vehicle ratio of $10 \% \sim 50 \%$ is taken as an example to compute the collision rate. And we use reduction extents of traffic collision rate to analyze the effect of the setting of the climbing lane, as shown in TABLE4.

Table 4. Effect Analysis for the Setting of the Climbing Lane with Slope Length of $1200 \mathrm{~m}$ and Gradient of 3\%

\begin{tabular}{|c|c|c|c|}
\hline $\begin{array}{c}\text { Traffic } \\
\text { Volume } \\
\text { (veh/h) }\end{array}$ & $\begin{array}{c}\text { Large } \\
\text { Vehicle } \\
\text { Ratio }\end{array}$ & $\begin{array}{c}\text { Collision Rate } \\
\text { Reduction } \\
\text { Extent }\end{array}$ & $\begin{array}{c}\text { Effectiveness } \\
\text { Evaluation } \\
\text { Result }\end{array}$ \\
\hline \multirow{4}{*}{$\mathbf{8 0 0}$} & $10 \%$ & $11.11 \%$ & Middle \\
\cline { 2 - 4 } & $20 \%$ & $21.43 \%$ & Good \\
\cline { 2 - 4 } & $30 \%$ & $31.25 \%$ & Excellent \\
\cline { 2 - 4 } & $40 \%$ & $23.81 \%$ & Good \\
\cline { 2 - 4 } & $50 \%$ & $16.67 \%$ & Middle \\
\hline \multirow{4}{*}{$\mathbf{1 0 0 0}$} & $10 \%$ & $23.53 \%$ & Good \\
\cline { 2 - 4 } & $20 \%$ & $26.32 \%$ & Good \\
\cline { 2 - 4 } & $30 \%$ & $36.00 \%$ & Excellent \\
\cline { 2 - 4 } & $40 \%$ & $26.47 \%$ & Good \\
\cline { 2 - 4 } & $50 \%$ & $13.51 \%$ & Middle \\
\hline
\end{tabular}

According to TABLE4, when the large vehicle ratio is $10 \%$ and the traffic volume is $1000 \mathrm{veh} / \mathrm{h} \sim 1200 \mathrm{veh} / \mathrm{h}$, setting climbing lane has good effect. When the traffic volume is relatively small or large, setting climbing lane has middle effect. The reasons are following: when the traffic volume is relatively small, the traffic flow is under free flow state and large vehicles slightly influence small vehicles. However, when the traffic volume is relatively large, the traffic flow is under saturated state, and setting climbing lane cannot effectively separate the large vehicles to reduce traffic collisions.

When the large vehicle ratio is $20 \% \sim 40 \%$ and the traffic volume is not more than $1200 \mathrm{veh} / \mathrm{h}$, setting climbing lane has excellent or good effect. This indicates that setting climbing lane has relatively good effect for improving traffic safety.

When the traffic volume is more than $1200 \mathrm{veh} / \mathrm{h}$, setting climbing lane has poorer effect along with the increment of the large vehicle ratio. This indicates that setting climbing lane cannot significantly improve the traffic safety. When the large vehicle ratio is increased as $50 \%$, setting climbing lane cannot improve the traffic safety of the upgrade section, but oppositely increase the traffic collision rate and reduce the traffic safety.

\section{Conclusion}

The effect of setting freeway climbing lane and the basis for the setting's specifics were systematically researched in this paper with the goal of traffic safety. The authors aimed to provide suggestions regarding the setting position and the setting method of the climbing lane. However, this study was limited to analyzing data from the angle of road and traffic condition. In reality, there are other influencing factors of the upgrade section such as traffic control condition, environment condition, and 
more. Future studies may look into including traffic control and environment conditions as variables to be considered for modeling. The main suggestions that can be drawn from this study are summarized by the following points.

Setting Position of the Climbing Lane: The start point of the climbing lane should be set at the position where the speed reduction of large vehicles is at $20 \mathrm{~km} / \mathrm{h}$. The end point needs to be set at the speed recovery position. It is also necessary to comprehensively consider the relation between the start-end points to ensure that these points are set at the positions with the features of good inter visibility, easy identification, and smooth transition. Moreover, the setting effect and the investment level must also be considered. A minimum length of $500 \mathrm{~m}$ for the climbing lane is suggested. When the calculated length for the climbing lane is less than $500 \mathrm{~m}$ (using the methods aforementioned), the setting of a climbing lane is not advised.

Setting Basis of the Climbing Lane: When the traffic volume is less than $1200 \mathrm{veh} / \mathrm{h}$, when the large vehicle ratio is less than $20 \%$, or when the large vehicle ratio is more than $40 \%$, setting a climbing lane on the upgrade section cannot improve traffic safety. So it is not advisable to set climbing lane although it is necessary to adopt such measures as lane limitation to improve the traffic safety of upgrade section; When the traffic volume exceeds $1200 \mathrm{veh} / \mathrm{h}$, the traffic flow on the upgrade section becomes saturated. In this case, the setting of the climbing lane can improve the traffic capacity but cannot effectively improve the traffic safety of the upgrade section. Furthermore, the setting of the climbing lane may increase the traffic collisions among vehicles, so it is not advisable to set the climbing lane under such conditions.

When the traffic volume does not exceed $1200 \mathrm{veh} / \mathrm{h}$ and the large vehicle ratio is $20 \% \sim 40 \%$, the setting of the climbing lane on the upgrade section can effectively improve the traffic safety; especially, when the large vehicle ratio is about $30 \%$, the positive effect is most obvious.

\section{References}

1. H. Rakha, B. Yu, Journal of Transportation Engineering 130, 6, 753-767, (2004)

2. B. Yu, Faculty of Virginia Polytechnic Institute and State University, (2005)

3. Q. Yang, Y. Zhang, Highway 9, 98-101, (2005)
4. G.O.N.G. Ni-na, Communications Standardization 12, 193-194, (2008)

5. L. Wang. Research on Setting Climbing Lane on Steep Sections of Mountain Road. Shan Dong University, (2010)

6. V. Shankar, F. Mannering, W. Barfield, Accident Analysis and Prevention 27, 3, 371-389, (1995)

7. A. Pomst, I. Reshetnik, Transport Research Part A 21, 6, 401-410, (1987)

8. G. Liang, R. Ma, X. Shen, Y. Liang, Journal of Chang'an University (Natural Science Edition) 34, 1, 23-30, (2014)

9. American Association of State Highway and Transportation Official. A Policy on Geometric Design of Highways and Streets. Washington DC: AASHTO, ( 2011)

10. R. Pal, K. C. Sinha, Transportation Research Record: Journal of the Transportation Research Board, No. 1640, Transportation Research Board of the National Academies, Washington, D. C, 1-9, (2007)

11. Japan Highway Public Corporation. Japan Highway Design Essentials. Shaanxi Travel \& Tourism Press, China, ( 1991)

12. Guidelines for Safety Audit of Highway. Publication JTG/T B05-2004.Ministry of Transport of the People's Republic of China, (2004)

13. Technical Standard of Highway Engineering. Publication JTG B01-2003. Ministry of Transport of the People's Republic of China, ( 2004)

14. Design Specification for Highway Alignment. Publication JTG D20-2006. Ministry of Transport of the People's Republic of China, (2006)

15. M. Parker Jr, and C. V. Zegeer, Observers Manual. Publication FHWA-IP-88-027. FHWA, U.S. Department of Transportation, (1989)

16. A. L. Vasconcelos, A. Seco, A. B. Silva, et al., Transportation Research Record: Journal of the Transportation Research Board, No. 2432, Transportation Research Board of the National Academies, Washington, D. C., 1-9, (2014)

17. J. So, I.K. Lim,Y.J. Kweon, Transportation Research Board of the National Academies, Washington, D. C., (2015)

18. PTV VISSIM User's Manual 5. 0. Planung Transport Verkehr AG, D-76131 Karlsruhe, Germany, (2007)

19. D. Gettman, L. Pu, T. Sayed, and S. G. Shelby. Surrogate Safety Assessment Model and Validation: Final Report. Publication FHWA-HRT-08-051. FHWA, U.S.Department of Transportation, (2008) 